\title{
Randomized controlled trial of oatmeal consumption versus noodle consumption on blood lipids of urban Chinese adults with hypercholesterolemia
}

Jian Zhang ${ }^{1 *}$, Lixiang Li ${ }^{1}$ Pengkun Song ${ }^{1}$, Chunrong Wang ${ }^{1}$, Qingqing Man ${ }^{1}$, Liping Meng ${ }^{1}$, Jenny Cai ${ }^{2}$ and Anne Kurilich ${ }^{3}$

\begin{abstract}
Background: Cardiovascular disease (CVD) is the leading cause of death in China and worldwide. Whole grain oats can reduce risk of CVD by reducing total and LDL-cholesterol, major risk factors for CVD. While this association has been established in many populations, data from Asian populations is limited. Thus, this study investigated the impact of oat consumption on cholesterol levels in Chinese adults. Male and female data from this work were previously published separately in mandarin in two Chinese journals. The combined male and female data were reanalyzed and are presented here.
\end{abstract}

Methods: A randomized, controlled, parallel-arm study was conducted at Beijing Hospital, Beijing china. Subjects were adults (men and women) with mild to moderate hypercholesterolemia. The oat group ( $n=85)$ consumed $100 \mathrm{grams}$ of instant oat cereal versus the control group $(n=81)$ who consumed 100grams of wheat flour-based noodles daily for 6 weeks. Laboratory and anthropometric measurements were conducted at baseline and at the end of the 6-week intervention.

Results: Dietary fiber intake increased significantly in the oat group compared to the control group at the end of the 6-week intervention. Total-, LDL-cholesterol and waist circumference decreased significantly in the oat group compared to the control. HDL-cholesterol decreased significantly in the control group versus the oat group. There were no significant changes in blood pressure, other anthropometric or laboratory measures between the two groups at the end of the intervention.

Conclusions: Instant oatmeal consumed daily for 6 weeks significantly increased fiber intake and decreased major risk factors for CVD in Chinese adults with hypercholesterolemia. Increased consumption of whole grains, including oats, should continue to be encouraged.

Keywords: Oats, Oatmeal, Cholesterol, Chinese adults

\section{Background}

Cardiovascular disease (CVD) is the leading cause of death in China [1] as well as worldwide [2]. Established risk factors for CVD include elevated total cholesterol (TC), elevated low density lipoprotein cholesterol (LDLC), low high density lipoprotein cholesterol (HDL-C)

\footnotetext{
* Correspondence: zhjian6708@yahoo.com.cn

'Chinese Center for Disease Control and Prevention, Beijing 100050, China

Full list of author information is available at the end of the article
}

and hypertension. These risk factors are modifiable by lifestyle factors including diet and exercise [3].

Epidemiological studies suggest that diets high in whole grains are associated with a reduced risk of CVD and mortality [4-7]. In China, recent changes to the traditional diet, including significant reductions in wholegrain intake (104g/day in 1982 to $24 \mathrm{~g} /$ day in 2002) may be contributing to the increased CVD mortality [8].

Wholegrain oats can significantly lower serum TC and LDL-C and reduce risk for CVD [9]. Authoritative regulatory bodies in several countries, including the United

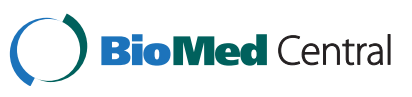


States, Canada, Europe and Malaysia, have reviewed the available evidence and allow a health claim on food labels regarding the relationship between oat consumption and a reduction in blood cholesterol concentration and reduced risk of CVD [10-13].

Data regarding impact of oat consumption on CVD risk factors in Asian populations, including the Chinese population, is limited. Therefore, the present study investigated the relationship between instant oatmeal intake and CVD risk factors in a sample of urban Chinese adults with mild to moderate hypercholesterolemia.

\section{Methods}

\section{Study design}

This was a randomized, controlled, parallel-arm study conducted at Beijing Hospital, Beijing China. Screening of potential study subjects was held in August and September 2008. The six week intervention was conducted from October 2008 through December 2008 during which the subjects visited the research site once per week. The study protocol was approved by the ethics committee of the Institute of Nutrition and Food Safety, Chinese center for Disease control and Prevention. Participants provided written informed consent before any study procedures were performed. Due to the nature of the food products serving as control (wheat noodles) and test (oatmeal) product, it was not possible to blind the subjects or the researchers, however, the statistician analyzing the data was blinded to the treatment groups.

\section{Study participants}

Based on the diagnostic standards in the Chinese Guidelines on Prevention and Treatment of Dyslipidemia in Adults[14] the selection criteria were as follows: (1)males and females 35 to 70 years of age; (2) serum total cholesterol $\geq 5.18 \mathrm{mM}$, low density lipoprotein cholesterol $\geq 3.37 \mathrm{mM}$; (3) no serious liver, kidney, digestive tract disease, diabetes or other metabolic diseases; (4) no use of cholesterol lowering medication or foods that have been approved by the China State Food and Drug Administration as functional foods with blood lipid lowering properties in the last 6 months; and (5) did not habitually consume oat products. Screening of study participants was done in August and September 2008. Based on data obtained from a basic health questionnaire, food frequency questionnaire and results of a fasting blood lipid test, 182 subjects (109 females, 73 males) were selected to participate and randomized to either the oat group or the control group. Participants were instructed to consume their normal diet during the study period. Participants who smoked could not have plans to change smoking habits during the treatment period.

\section{Diet and study product}

A 3-day 24-hour dietary recall was conducted at the start and end of the study to determine food and nutrient intake. The 24 hour dietary recall questionnaire was validated in the 2002 Chinese Nutrition and Health Survey project. SAS 8.2 software was used to calculate nutrient intake based on Chinese Food composition Table.

Prior to beginning the intervention, all participants were provided with basic nutrition counseling following the Chinese Food Pagoda guidelines which consisted of advice to consume a variety of foods including cereals, fruits, vegetables, dairy and lean meats and to reduce sodium and limit alcohol intake. Participants were instructed not to change their exercise habits and to maintain their normal dietary habits with the exception of replacing a portion of a staple food product (rice, steamed bread, noodles, etc.) with the intervention product (oats or wheat noodles). Oatmeal (Quaker Instant Oatmeal produced by PepsiCo Foods (China) co., Ltd.) was packaged in $200 \mathrm{~g}$ (dry wt) packages and 4 packages were provided to participants one week followed by 3 packages the next week. Participants receiving the oatmeal were instructed to prepare $1 / 2$ a package $(\sim 100 \mathrm{~g}$ dry $\mathrm{wt}$, providing approximately $3.6 \mathrm{~g}$ soluble fiber) each day according to the on-pack preparation instructions (with hot water or milk). Consumption of the prepared amount could be split across two or three meals each day for the six week intervention period. Wheat noodles ("Shengchu" brand processed wheat flour based noodles) were purchased in $450 \mathrm{~g}$ packages at the local grocery store and distributed to participants on a weekly basis. Participants were instructed to prepare and consume 100g (dry wt) each day. All subjects in the control group were shown a $100 \mathrm{~g}$ portion of dry noodles that had been weighed on a scale to help them visualize the amount that they should prepare and consume each day. Wheat based noodles are a standard staple in the diets of this population and this amount can easily be consumed in one meal. Each participant was asked to record the quantity of the test food they consumed each day. The oat and noodle packs were distributed once each week to facilitate weekly communication with the participants and discuss intake of food and any relevant concerns or issues linked with the daily oat or noodle consumption.

\section{Anthropometric and laboratory measurements}

Anthropometric measurements were conducted at baseline and at the end of the six week intervention period. Standing height was measured. Participant weight was measured while wearing light weight clothing and without shoes. Waist circumference was measured on a horizontal plane at the level of the iliac crest using a non-stretch anthropometric tape. Two consecutive readings of blood pressure were taken according to 
methods described in the 2010 Chinese Guidelines for the management of hypertension [15] with the subject in a seated position after 5 minutes of rest. The mean of the two measurements was used for statistical analysis. Fasting blood samples were collected at baseline and at the end of the intervention period. Blood biochemical parameters were measured using a Shimazu 7600 fully automatic biochemical analyzer and included serum total cholesterol (TC), serum triglycerides (TG), high density lipoprotein cholesterol (HDL-C), low density lipoprotein cholesterol (LDL-C), apolipoprotein A1 (ApoA1), apolipoprotein $\mathrm{B}(\mathrm{ApoB})$ and plasma glucose.

\section{Statistical methods}

The statistician was blinded to the treatment groups. All statistical summaries and analyses were performed using SAS V 8.2 for windows (SAS Institute, cary, NC). Categorical data were summarized as frequencies and proportions within each group. When analyzing for group differences among the categories, a 2-sided Fisher's exact test was used. Effect of intervention on dietary composition was analyzed as change from baseline to minimize the bias of any baseline differences. Baseline data and changes from baseline were analyzed using f-test from analysis of covariance (ANCOVA) where the group effect was fixed and the covariates were age, sex, smoking status, alcohol consumption, educational status, and medication use. The effects of intervention on anthropometrics, blood pressure, lipids and glucose were also analyzed for baseline group differences and as change from baseline after six weeks. Summaries of these outcomes were presented as least squares means (LSM) and standard errors (SE) obtained from the ANCOVA model to account for any baseline unbalance in the groups and the effects of the covariates. Statistical significance was set at $\mathrm{P}<0.05$.

\section{Results}

\section{Study compliance}

During the study period there were 9 subjects from the control group and 7 subjects from the oat group that dropped out or were eliminated due to non-compliance with the study protocol. Two subjects from each group were eliminated due to incorrect recording of food amounts as determined by unreasonably low calculated daily calorie intake values $(<500 \mathrm{kcal} /$ day), while $2 \mathrm{sub}-$ jects from the control group and 1 subject from the oat group were eliminated due to use of products that may reduce serum cholesterol. In addition, 5 subjects from control group and 4 subjects from the oat group dropped out due to personal reasons such as losing interest in the study or travel requirements. A total of 85 subjects in the oat group and 81 subjects in the control group were included in the final data analysis. There were no adverse events reported during the intervention period except for some complaints about the taste of the oat product.

Baseline characteristics of the two test groups are provided in Table 1 . There were no statistically significant differences between groups for any of the demographic characteristics or any of the anthropometric measures. There was a statistical difference between groups in ApoB levels at baseline with the oat group having slightly higher levels than the control group ( $\mathrm{p}=0.044)$. However, both groups were within the normal reference range of $0.60-1.94 \mathrm{~g} / \mathrm{L}$.

Covariates were evaluated in the analysis of baseline characteristics to determine their effect on each measure prior to intervention. Age was a significant covariate in systolic blood pressure and blood glucose. Sex was a significant covariate in height, waist circumference, weight, systolic blood pressure, diastolic blood pressure, total cholesterol, triglycerides, HDL-C and ApoA1 levels. Smoking status was a significant covariate in total cholesterol, LDL-C and ApoB levels. Alcohol consumption was a significant covariate in height and diastolic blood pressure. Education status was a significant covariate in waist circumference, BMI and systolic blood pressure.

\section{Table 1 Baseline characteristics of subjects}

\begin{tabular}{|c|c|c|c|}
\hline Characteristic & $\begin{array}{l}\text { Oat group } \\
(n=85)\end{array}$ & $\begin{array}{l}\text { Control group } \\
(n=81)\end{array}$ & $\begin{array}{l}\text { P Between } \\
\text { groups }\end{array}$ \\
\hline Age $(y)^{1}$ & $52.7(0.69)$ & 53.7 (0.73) & 0.341 \\
\hline Male $(\%)^{2}$ & $38.8 \%$ & $39.5 \%$ & $>0.999$ \\
\hline Height $(\mathrm{cm})^{3}$ & $165.1(0.49)$ & $165.3(0.50)$ & 0.788 \\
\hline Waist circumference $(\mathrm{cm})^{3}$ & $86.7(0.92)$ & $86.9(0.94)$ & 0.887 \\
\hline Weight $(\mathbf{k g})^{3}$ & $69.7(0.94)$ & $69.8(0.97)$ & 0.948 \\
\hline Body mass Index ${ }^{3}$ & $25.5(0.32)$ & $25.5(0.33)$ & 0.964 \\
\hline Smoker (\%) ${ }^{1}$ & $18.8 \%$ & $13.6 \%$ & 0.405 \\
\hline Alcohol Use (\%) ${ }^{1}$ & $32.9 \%$ & $29.6 \%$ & 0.738 \\
\hline Medication Use (\%) ${ }^{1}$ & $50.6 \%$ & $56.8 \%$ & 0.441 \\
\hline Systolic BP $(\mathrm{mmHg})^{3}$ & $124.7(1.74)$ & $129.0(1.78)$ & 0.085 \\
\hline Diastolic BP ${ }^{3}$ & $80.3(1.06)$ & $79.7(1.09)$ & 0.689 \\
\hline Total cholesterol $(\mathrm{mmol} / \mathrm{L})^{3}$ & $6.26(0.074)$ & $6.09(0.076)$ & 0.129 \\
\hline Triglycerides $(\mathrm{mmol} / \mathrm{L})^{3}$ & $2.06(0.103)$ & $1.89(0.106)$ & 0.279 \\
\hline 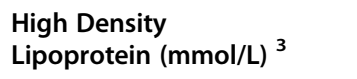 & $1.47(0.029)$ & $1.51(0.030)$ & 0.337 \\
\hline 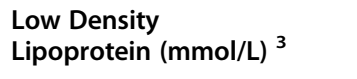 & $4.30(0.075)$ & $4.17(0.077)$ & 0.237 \\
\hline Plasmaglucose $(\mathrm{mmol} / \mathrm{L})^{3}$ & $5.63(0.097)$ & $5.47(0.099)$ & 0.277 \\
\hline Apo A1 $(g / L)^{3}$ & $1.59(0.032)$ & $1.57(0.033)$ & 0.554 \\
\hline Apo B $(g / L)^{3}$ & $0.96(0.017)$ & $0.91(0.018)$ & 0.044 \\
\hline
\end{tabular}

${ }^{1}$ LSM (SE) and p-value obtained from ANOVA.

${ }^{2}$ Proportion and p-value obtained from 2-sided Fisher's Exact test. ${ }^{3}$ LSM (SE) and p-value obtained from ANCOVA, where covariates were age, sex, smoking status, alcohol consumption, education status, medication use. 
Table 2 Diet compositions

\begin{tabular}{|c|c|c|c|}
\hline \multirow[t]{2}{*}{ Diet characteristic } & \multicolumn{3}{|c|}{ 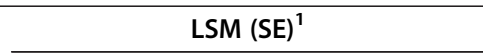 } \\
\hline & $\begin{array}{l}\text { Oat group } \\
(\mathrm{n}=85)\end{array}$ & $\begin{array}{c}\text { Control group } \\
(n=81)\end{array}$ & $\begin{array}{l}\text { P Between } \\
\text { groups }\end{array}$ \\
\hline $\begin{array}{l}\text { Energy }(\mathrm{MJ} / \mathrm{d}) \text { change } \\
\text { from Baseline }\end{array}$ & $0.30(0.193)$ & $0.32(0.198)$ & 0.942 \\
\hline Baseline & $7.6(0.20)$ & $7.7(0.20)$ & 0.687 \\
\hline Week 6 & $7.9(0.20)$ & $8.1(0.20)$ & \\
\hline $\begin{array}{l}\text { Protein }(g / d) c h a n g e \\
\text { from Baseline }\end{array}$ & $4.6(1.97)$ & $1.7(2.02)$ & 0.315 \\
\hline Baseline & $64.8(1.83)$ & $61.1(1.88)$ & 0.168 \\
\hline Week 6 & $69.3(1.82)$ & $62.8(1.86)$ & \\
\hline $\begin{array}{l}\text { Protein (\% energy) change } \\
\text { from Baseline }\end{array}$ & $0.45(0.309)$ & $-0.14(0.317)$ & 0.191 \\
\hline Baseline & $14.3(0.24)$ & $13.3(0.25)$ & 0.004 \\
\hline Week 6 & $14.8(0.28)$ & $13.1(0.29)$ & \\
\hline $\begin{array}{l}\text { Fat }(g / d) \text { change from } \\
\text { Baseline }\end{array}$ & $2.9(2.58)$ & $1.2(2.64)$ & 0.634 \\
\hline Baseline & $62.5(2.77)$ & $61.7(2.84)$ & 0.841 \\
\hline Week 6 & $65.5(2.52)$ & $62.9(2.59)$ & \\
\hline $\begin{array}{l}\text { Fat (\% energy) change } \\
\text { from Baseline }\end{array}$ & $0.36(0.817)$ & $-0.58(0.837)$ & 0.428 \\
\hline Baseline & $30.3(0.86)$ & $29.4(0.88)$ & 0.472 \\
\hline Week 6 & $30.6(0.77)$ & $28.8(0.79)$ & \\
\hline $\begin{array}{l}\text { Cholesterol }(\mathrm{mg} / \mathrm{d}) \\
\text { change from Baseline }\end{array}$ & $-39.7(21.73)$ & $-38.5(22.27)$ & 0.968 \\
\hline Baseline & $312(19.1)$ & $292(19.5)$ & 0.460 \\
\hline Week 6 & $272(18.1)$ & $253(18.5)$ & \\
\hline $\begin{array}{l}\text { SFA (\% energy) change } \\
\text { from Baseline }\end{array}$ & $-0.66(0.261)$ & $-0.34(0.267)$ & 0.389 \\
\hline Baseline & $8.7(0.27)$ & $7.9(0.27)$ & 0.051 \\
\hline Week 6 & $8.0(0.24)$ & $7.6(0.25)$ & \\
\hline $\begin{array}{l}\text { MUFA (\% energy) change } \\
\text { from Baseline }\end{array}$ & $0.21(0.414)$ & $-0.52(0.425)$ & 0.218 \\
\hline Baseline & $12.6(0.41)$ & $12.3(0.42)$ & 0.602 \\
\hline Week 6 & $12.9(0.39)$ & $11.8(0.40)$ & \\
\hline $\begin{array}{l}\text { PUFA (\% energy) change } \\
\text { from Baseline }\end{array}$ & $0.38(0.388)$ & $0.28(0.398)$ & 0.868 \\
\hline Baseline & $7.9(0.39)$ & $8.2(0.40)$ & 0.632 \\
\hline Week 6 & $8.3(0.34)$ & $8.5(0.35)$ & \\
\hline $\begin{array}{l}\text { Carbohydrate }(g / d) \text { change } \\
\text { from Baseline }\end{array}$ & $14.2(7.12)$ & $16.5(7.30)$ & 0.825 \\
\hline Baseline & $247(6.4)$ & $259(6.6)$ & 0.173 \\
\hline Week 6 & $260(7.2)$ & $276(7.4)$ & \\
\hline $\begin{array}{l}\text { Carbohydrate (\% energy) } \\
\text { change from Baseline }\end{array}$ & $0.41(0.859)$ & $1.08(0.881)$ & 0.588 \\
\hline Baseline & $54.9(0.92)$ & $56.6(0.94)$ & 0.197 \\
\hline Week 6 & $55.3(0.83)$ & $57.7(0.85)$ & \\
\hline
\end{tabular}

Table 2 Diet compositions (Continued)

\begin{tabular}{|c|c|c|c|}
\hline $\begin{array}{l}\text { Dietary fiber }(g / d) \text { change } \\
\text { from Baseline }\end{array}$ & $7.1(0.60)$ & $1.4(0.62)$ & $<0.001$ \\
\hline Baseline & $12.2(0.52)$ & $11.4(0.53)$ & 0.296 \\
\hline Week 6 & $19.3(0.55)$ & $12.9(0.56)$ & \\
\hline \multicolumn{4}{|c|}{$\begin{array}{l}\text { 1 LSM (SE) and p-value obtained from ANCOVA, where covariates were age, } \\
\text { sex, smoking status, alcohol consumption, education status, medication use. }\end{array}$} \\
\hline \multicolumn{4}{|c|}{$\begin{array}{l}\text { Medication use was not a significant covariate for any } \\
\text { characteristics. Due to the mixed and overlapping influ- } \\
\text { ences of these covariates, all covariates were kept in the } \\
\text { subsequent analyses of dietary compositions and changes } \\
\text { in anthropometric and lipid measures after } 6 \text { weeks of } \\
\text { intervention. }\end{array}$} \\
\hline
\end{tabular}

\section{Dietary intake}

Dietary compositions at baseline and after 6 weeks of intervention are presented in Table 2. Baseline dietary composition was consistent between the groups for all components except percent of energy from dietary protein which was significantly higher among the oat group than the control group $(\mathrm{p}=0.004)$. After 6 weeks of intervention, dietary fiber significantly increased among the oat group compared to the control group ( $<<0.001)$. No other changes in composition were notable between the groups.

\section{Anthropometric measures and blood pressure}

Anthropometric measures and blood pressure after 6 weeks and as change from baseline are presented in Table 3. Waist circumference significantly decreased after 6weeks in the oat group compared to the control group $(p=0.002)$. No other measures changed significantly.

\section{Serum lipids and plasma glucose}

Serum lipids and plasma glucose after 6weeks and as change from baseline are presented in Table 4. The oat group showed significant decreases in total cholesterol $(\mathrm{p}=0.015)$ and LDL-C $(\mathrm{p}=0.028)$ compared to the control group. In addition, HDL-C decreased significantly in the control group compared to the oat group $(\mathrm{p}=0.017)$. Effects of intervention were observed for these same lipids when summarized as a percentage change from baseline (Figure 1). There were no significant differences in plasma glucose levels between the two groups.

\section{Discussion}

The results of this study show that when instant oats are consumed daily in place of another staple food (rice, steamed bread, noodles, etc.) compared to wheat noodles as replacement for another staple food, there is a significant increase in dietary fiber intake and significant decreases in waist circumference, TC and LDL-C in 
Table 3 Changes in anthropometric measures and blood pressure during study period

\begin{tabular}{|c|c|c|c|}
\hline \multirow[t]{2}{*}{ Measures } & \multicolumn{3}{|c|}{ LSM (SE) $^{1}$} \\
\hline & $\begin{array}{l}\text { Oat group } \\
(n=85)\end{array}$ & $\begin{array}{l}\text { Control group } \\
(n=81)\end{array}$ & $\begin{array}{l}\mathrm{P} \text { Between } \\
\text { groups }\end{array}$ \\
\hline $\begin{array}{l}\text { Waist circumference } \\
(\mathrm{cm}) \text { change } \\
\text { from Baseline }\end{array}$ & $-1.27(0.473)$ & $0.85(0.485)$ & 0.002 \\
\hline Baseline & 86.7 (0.92) & $86.9(0.94)$ & 0.887 \\
\hline Week 6 & $85.4(0.82)$ & $87.7(0.84)$ & \\
\hline $\begin{array}{l}\text { Weight }(\mathbf{k g}) \text { change } \\
\text { from Baseline }\end{array}$ & $0.46(0.306)$ & $0.67(0.313)$ & 0.621 \\
\hline Baseline & 69.7(0.94) & $69.8(0.97)$ & .0948 \\
\hline Week 6 & $69.8(0.93)$ & $70.4(0.96)$ & \\
\hline $\begin{array}{l}\text { Body mass Index } \\
\text { change from Baseline }\end{array}$ & $0.04(0.092)$ & $0.25(0.094)$ & 0.108 \\
\hline Baseline & $25.5(0.32)$ & $25.5(0.33)$ & 0.964 \\
\hline Week 6 & $25.6(0.32)$ & $25.7(0.32)$ & \\
\hline $\begin{array}{l}\text { Systolic Blood Pressure } \\
\text { change from Baseline }\end{array}$ & $1.01(1.120)$ & $0.85(1.477)$ & 0.919 \\
\hline Baseline & $124.7(1.74)$ & $129.0(1.78)$ & 0.085 \\
\hline Week 6 & $125.7(1.65)$ & $129.9(1.69)$ & \\
\hline $\begin{array}{l}\text { Diastolic Blood Pressure } \\
\text { change from Baseline }\end{array}$ & $-0.13(0.916)$ & $0.76(0.938)$ & 0.500 \\
\hline Baseline & $80.3(1.06)$ & 79.7 (1.09) & 0.689 \\
\hline Week 6 & $80.1(0.97)$ & $80.4(1.00)$ & \\
\hline
\end{tabular}

1 LSM (SE) and p-value obtained from ANCOVA, where covariates were age, sex, smoking status, alcohol consumption, education status, medication use.

Chinese adults with moderate hypercholesterolemia. During the intervention period there was a $6.2 \%$ decrease in TC for the oat group compared to a $2.3 \%$ decrease in the control group. There was also an $8.4 \%$ decrease in LDL-C for the oat group compared to a $3.5 \%$ decrease in the control group.

The oat group consumed 100 grams of instant oats per day which provided $\sim 3.6$ grams of soluble fiber. Oat products containing $\beta$-glucan soluble fiber decrease TC and LDL-C by altering bile acid metabolism and increasing bile acid excretion [16,17]. The reductions in TC and LDL-C observed in this study are similar to previous reports in free living individuals. Van Horn et al. [18] reported a $5.2 \%$ reduction in TC in healthy adults consuming $60 \mathrm{~g} /$ day of either oat bran or oatmeal for 6weeks as part of a low fat diet. Karmally and colleagues [19] provided 3g/day of $\beta$-glucan from ready-to-eat (RTE) oat cereal for 6 weeks to adults with mild to moderate hypercholesterolemia and observed reductions of $4.5 \%$ in TC and $5.3 \%$ in LDL-C. In a recent trial a $5.4 \%$ reduction in $\mathrm{TC}$ along with an $8.7 \%$ decrease in LDL-C was reported following consumption of $3 \mathrm{~g} /$ day of $\beta$-glucan from ready-to-eat (RTE) oat cereal for 12 weeks in overweight or obese adults [20]. A 2007 cochrane review reported
Table 4 Changes in lipids and glucose during study period

\begin{tabular}{|c|c|c|c|}
\hline \multirow[t]{2}{*}{ Measures } & \multicolumn{3}{|c|}{$\operatorname{LSM}(\mathrm{SE})^{1}$} \\
\hline & $\begin{array}{l}\text { Oat group } \\
(n=85)\end{array}$ & $\begin{array}{c}\text { Control group } \\
(n=81)\end{array}$ & $\begin{array}{l}P \text { Between } \\
\text { groups }\end{array}$ \\
\hline $\begin{array}{l}\text { Total cholesterol } \\
\text { (mmol/L) change } \\
\text { from Baseline }\end{array}$ & $-0.41(0.071)$ & $-0.15(0.073)$ & 0.015 \\
\hline Baseline & $6.26(0.074)$ & $6.09(0.076)$ & 0.129 \\
\hline Week 6 & $5.85(0.085)$ & $5.94(0.087)$ & \\
\hline $\begin{array}{l}\text { Triglycerides } \\
\text { (mmol/L) change } \\
\text { from Baseline }\end{array}$ & $-0.15(0.089)$ & $-0.04(0.091)$ & 0.404 \\
\hline Baseline & $2.06(0.103)$ & $1.89(0.106)$ & 0.279 \\
\hline Week 6 & $1.91(0.107)$ & $1.85(0.110)$ & \\
\hline $\begin{array}{l}\mathrm{HDLC}(\mathrm{mmol} / \mathrm{L}) \text { change } \\
\text { from Baseline }\end{array}$ & $-0.04(0.018)$ & $-0.10(0.018)$ & 0.017 \\
\hline Baseline & $1.47(0.029)$ & $1.51(0.030)$ & 0.337 \\
\hline Week 6 & $1.43(0.032)$ & $1.41(0.033)$ & \\
\hline $\begin{array}{l}\text { LDLC (mmol/L) change } \\
\text { from Baseline }\end{array}$ & $-0.39(0.067)$ & $-0.17(0.069)$ & 0.028 \\
\hline Baseline & $4.30(0.075)$ & $4.17(0.077)$ & 0.237 \\
\hline Week 6 & $3.91(0.081)$ & $4.00(0.083)$ & \\
\hline $\begin{array}{l}\text { Apo A1 (g/L) change } \\
\text { from Baseline }\end{array}$ & $0.02(0.29)$ & $-0.02(0.029)$ & 0.432 \\
\hline Baseline & $1.59(0.032)$ & $1.57(0.033)$ & 0.554 \\
\hline Week 6 & $1.61(0.035)$ & $1.55(0.036)$ & \\
\hline $\begin{array}{l}\text { Apo B }(g / L) \text { change } \\
\text { from Baseline }\end{array}$ & $-0.06(0.016)$ & $-0.02(0.017)$ & 0.102 \\
\hline Baseline & $0.96(0.017)$ & $0.91(0.018)$ & 0.044 \\
\hline Week 6 & $0.91(0.017)$ & $0.89(0.017)$ & \\
\hline $\begin{array}{l}\text { Plasma glucose } \\
\text { (mmol/L) change } \\
\text { from Baseline }\end{array}$ & $-0.30(0.057)$ & $-0.17(0.059)$ & 0.118 \\
\hline Baseline & $5.63(0.097)$ & $5.47(0.099)$ & 0.277 \\
\hline Week 6 & $5.34(0.088)$ & $5.29(0.090)$ & \\
\hline
\end{tabular}

1 LSM (SE) and p-value obtained from ANCOVA, where covariates were age, sex, smoking status, alcohol consumption, education status, medication use.

results of a meta-analysis based on 8 randomized clinical trials that used oats as a wholegrain intervention. A significant effect of oat consumption to lower both TC $(\mathrm{P}=.0005)$ and LDL-C concentrations $(\mathrm{P}=.0008)$ was observed. The mean percentage reduction in LDL-C from baseline (95\% confidence interval) was $4.9 \%$ (7.6\% to $2.4 \%)$ [9].

The prevalence of dyslipidemia in Chinese adults has been reported to be $2.9 \%$ for hypercholesterolemia (serum TC $\geq 5.18 \mathrm{mmol} / \mathrm{L}$ ) and $11.9 \%$ for hypertriglyceridemia (serum TG $\geq 1.70 \mathrm{mmol} / \mathrm{L}$ ) based on a nationally representative sample of subjects [21]. However, certain subgroups of the population have a higher reported prevalence of hypercholesterolemia. The prevalence is 


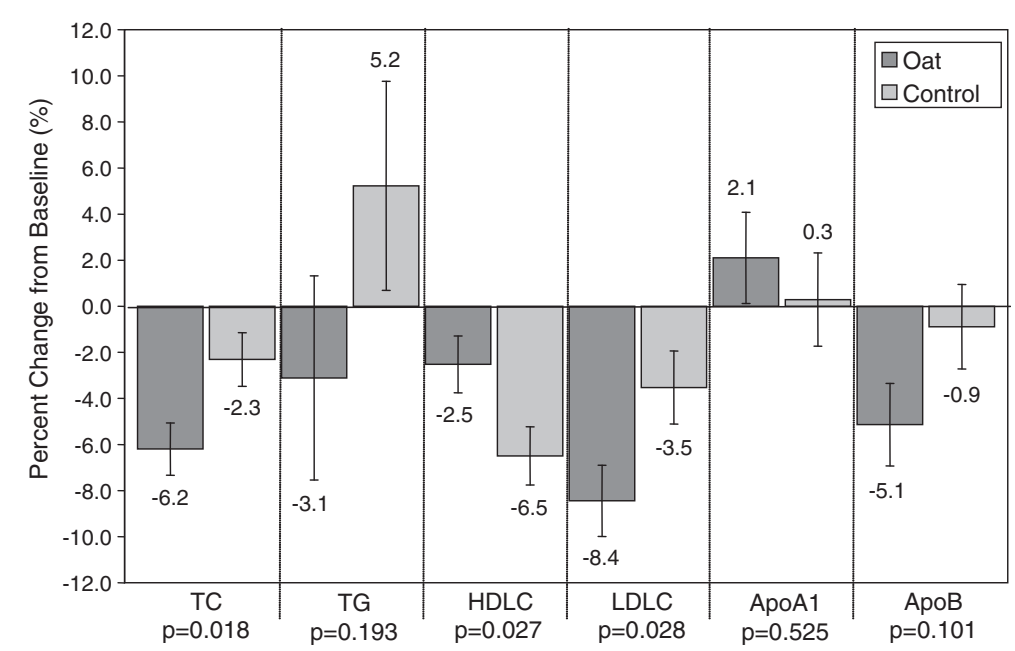

Figure 1 Percentage of change in lipids.

higher in adults over 60 years of age and has been reported to be $20.2 \%$ in males and $38.7 \%$ in females in this age group [22]. The prevalence of dyslipidemia has also been reported to be higher for urban (21\%) compared to rural (17.7\%) Chinese adults [21].The reduction in LDL-C observed in this study is of the magnitude to reduce risk of $\mathrm{CHD}$ since every $1 \%$ reduction in $\mathrm{LDL}-\mathrm{C}$ is associated with a decreased risk for $\mathrm{CHD}$ of $1 \%$ to $3 \%$ $[23,24]$.

A dietary pattern characterized by a high intake of vegetables, fruit and soy is one protective lifestyle factor associated with a marked decreased risk of coronary heart disease, cerebrovascular disease, and overall CVD mortality in Chinese men and women [25]. The traditional Chinese diet included a high intake of vegetables and coarse grains, which are the main sources of total and insoluble dietary fiber in the Chinese population $[8,26]$. However significant dietary changes have occurred in recent years which may be contributing to the prevalence of hypercholesterolemia within the population. The national average daily intake of cereals decreased from 510g/day in 1982 to $402 \mathrm{~g} /$ day in 2002. The amount of coarse grains decreased from 104g/day to $24 \mathrm{~g} /$ day in the same time period [8]. Average intake of total dietary fiber decreased from 22.6g/day in 1989 to $18.1 \mathrm{~g} /$ day in 2006 and insoluble dietary fiber intake decreased from $15.1 \mathrm{~g} /$ day in 1989 to $11.9 \mathrm{~g} /$ day in 2006 [26]. The 2007 Chinese food based dietary guidelines (FBDGs) issued by the Chinese Nutrition Society include a recommendation to include an appropriate amount of coarse grains. The proposed guidelines recommend a coarse grain intake, including whole grains, of no less than 50 grams per day for adults [8]. In this study the oat group had a significant increase in dietary fiber intake (7.1 grams/day) compared to the control group (1.4grams/day, $\mathrm{p}<0.001)$ during the treatment period. Intake of course grains was not calculated in this study.

The control group had a significant decrease in HDL-C concentration compared to the oat group during the intervention period $(\mathrm{p}=0.017)$. Dietary factors that impact HDL-C concentration include total fat and trans fat intakes along with the ratio of dietary saturated to unsaturated fat. The decrease in HDL-C in this study is puzzling since there were no significant changes in energy or total, saturated, mono- or poly-unsaturated fat intakes during the intervention period. There also was no significant change in ApoA-1 observed during the treatment period in this study. ApoA-1 concentration is also influenced by the ratio of polyunsaturated to saturated fat [27].

Waist circumference decreased $1.27 \mathrm{~cm}$ in the oat group compared to a $0.85 \mathrm{~cm}$ increase in the control group $(\mathrm{p}=0.002)$. Abdominal obesity is strongly associated with metabolic disturbances such as hypertriglyceridemia and insulin resistance [28]. Consumption of whole grains has been associated with smaller waist circumference in population studies [29,30]. Maki et al [20] reported a $\sim 1.5 \mathrm{~cm}$ reduction in waist circumference in overweight adults consuming $3 \mathrm{~g} /$ day of $\beta$-glucan for 12 weeks from RTE oat cereal. The clinical implications of a reduction in waist circumference without simultaneous changes in BMI or weight should be investigated.

There was no significant effect of oat consumption on blood pressure at the end of the 6 week treatment period in this study. Previous studies have reported mixed results of the effect of oats, $\beta$-glucan or whole grains on blood pressure. Keenan et al [31] reported reduced systolic and diastolic blood pressure in a pilot trial with oats. Whole-grain diets reduced blood pressure in mildly hypercholelsterolemic men and women [32]. Other 
investigators reported no effect on blood pressure after consumption of foods containing oat $\beta$-glucan [33], oats [34] and RTE oat cereal [20]. One confounding factor in this study is that slightly more than $50 \%$ of the total subjects were using medications including antihypertensive medication during the intervention.

One limitation of this study is exercise/activity levels were not reported however the subjects were instructed not to make any changes to their habitual diet or other lifestyle factors during the intervention. Another limitation is that antihypertensive medications were allowed during the trial and therefore the impact of the oat intervention on blood pressure was confounded. As the soluble fiber content of the diet before and after intervention could not be calculated, it is not possible to determine if there were changes to soluble dietary fiber intake over the course of the study.

\section{Conclusions}

Consumption of 100 grams of instant oatmeal per day significantly reduced TC, LDL-C and waist circumference in moderately hypercholesterolemic Chinese men and women. Replacement of a staple food with oatmeal significantly increased dietary fiber intake. Recent Chinese dietary guidelines include a recommendation to consume an appropriate amount of coarse grains including whole grains. The results of this study demonstrate that consumption of a wholegrain oat cereal has beneficial effects on risk factors for CVD.

\section{Abbreviations \\ CVD: Cardiovascular Disease; TC: Total cholesterol; LDL-C: Low Density Lipoprotein cholesterol; HDL-C: High Density Lipoprotein cholesterol; TG: Triglycerides; ApoA1: Apolipoprotein A1; ApoB: Apolipoprotein B; ANCOVA: Analysis of covariance; LSM: Least Square mean; SE: Standard Error; RTE: Ready To Eat; FBDGs: Food Based Dietary Guidelines.}

\section{Competing interests}

Authors AK and JC are employees of PepsiCo, Inc. and Pepsi Co china Foods, respectively.

Authors JZ, LL, PS, QM, LM and CW are employees of Institute of Nutrition and Food Safety, Chinese center for Disease control and Prevention, and declare no conflicts of interests.

\section{Authors' contributions}

The study was designed by JZ. LL, QM and CW carried out the study and collected the data (under the supervision of JZ). PS was responsible for the dietary survey and nutrient calculations. LM and AK were responsible for data analyses. JZ and AK were responsible for interpretation of results and manuscript writing. JC, AK and JZ reviewed manuscript drafts and the final manuscript. All authors read and approved the final manuscript.

\section{Acknowledgements}

The authors thank gang Hu and Jie Wei from Beijing Hospital for their assistance with subject recruitment and biochemical measurements, and Susan Spruill from Applied Statistics and consulting for biostatistics consultation. Funding for this project was provided by Xin Tan Health Research Development center (project no. 20080101).Pepsi Co china Foods provided the Quaker Instant Oatmeal.

\section{Author details}

${ }^{1}$ Chinese Center for Disease Control and Prevention, Beijing 100050, China. ${ }^{2}$ PepsiCo China Foods, 168 Xizhangmiddle Road, Shanghai 200001, China.

${ }^{3}$ Long Term Research, PepsiCo Inc, 617w.main St, Barrington, IL 60010, USA.

Received: 1 March 2012 Accepted: 28 June 2012

Published: 6 August 2012

\section{References}

1. National center for Health Statistics and the American Heart Association: Facts about cardiovascular disease [abstract]. Circulation 1992, 85:A103.

2. World Health Organization: 1990 World Health Statistics Annual. Geneva: World Health Organization; 1991. ISBN 10:92404678905.

3. Krauss RM, Eckel RH, Howard B, Appel L, Daniels SR, Deckelbaum RJ, Erdman JW Jr, Kris-Etherton P, Goldberg IJ, Kotchen TA, Lichtenstein AH, Mitchw E, Mullis R, Robinson K, Wylie-Rosett J, St Jeor S, Suttie J, Tribble DL, Bazzarre TL: AHA Dietary guidelines: revision 2000: A statement for healthcare professionals from the Nutrition committee of the American Heart Association. Circulation 2000, 102:2284-99.

4. He J, Klag MJ, Whelton PK, Mo JP, Chen JY, Qian MC, Mo PS, He GQ: Oats and buckwheat intakes and cardiovascular disease risk factors in an ethnic minority of china. Am J Clin Nutr 1995, 61:366-372.

5. Liu S, Stampfer MJ, Hu FB, Giovannucci E, Rimm E, Manson JE, Hennekens CH, Willett WC: Whole-grain consumption and risk of coronary heart disease: results from the Nurses' Health Study. Am J Clin Nutr 1999, 70:412-419.

6. Mellen PB, Walsh TF, Herrington DM: Whole grain intake and cardiovascular disease: a meta-analysis. Nutr Metab Cardiovasc Dis 2008, 18:283-290.

7. Jacobs DR, Pereira MA, Meyer KA, Kushi LH: Fiber from whole grains, but not refined grains, is inversely associated with all-cause mortality in older women: the lowa women's health study. J Am Coll Nutr 2000, 19:326S-330S

8. Ge K: The transition of Chinese dietary guidelines and food guide pagoda. Asia Pac J Clin Nutr 2011, 20:439-446.

9. Kelly SAM, Summerbellc D, Brynes A, Whittaker V, Frost G: Whole grain cereals for coronary heart disease. Cochrane Database of Systematic Reviews 2007, (2). doi:Art. No.:CD005051. DOI: 10.1002/14651858.CD005051. pub2.

10. Andon MB, Anderson JW: State of the art reviews: the oatmealcholesterol connection: 10 years later. Am J Lifestyle Med 2008, 2:51-57.

11. Bureau of Nutritional Sciences, Food Directorate, Health Products and Food Branch, Health Canada: Oat Products and cholesterol Lowering. Summary of Assessment of a Health claim About Oat Products and Blood cholesterol Lowering. 2010. http://hc-sc.gc.ca/fn-an/label-etiquent/claims-reclam/assessevalu/oat-avoine-eng.php.

12. Scientific opinion on the substantiation of a health claim related to oat beta-glucan and lowering blood cholesterol and reduced risk of (coronary) heart disease pursuant to Article 14 of Regulation (EC) No 1924/2006. EFSA Journal 2010, 8:1885-1900.

13. Technical working group on Nutrition guidelines: National coordinating committee on Health and Nutrition. Ministry of Health Malaysia: Malaysian Dietary Guidelines. Malaysia; 2010.

14. Joint committee for compiling Chinese guidelines on Prevention and Treatment of Dyslipidemia in Adults: Chinese guidelines on Prevention and Treatment of Dyslipidemia in Adults. Chinese Journal of cardiology 2007, 35(5):390-409.

15. Liu LS: The 2010 Chinese Guidelines for the management of hypertension. Chinese Journal of Hypertension 2011, 19(8):701-743.

16. Marlett JA, Hosig KB, Vollendorf NW, Shinnick FL, Haack VS, Story JA: Mechanism of serum cholesterol reduction by oat bran. Hepatology 1994 , 20:1450-1457.

17. Lia A, Hallmans G, Sandberg AS, Sundberg B, Aman P, Andersson H: Oat beta-glucan increases bile acid excretion and a fiber-rich barley fraction increases cholesterol excretion in ileostomy subjects. Am J Clin Nutr 1995, 62:1245-1251.

18. Van Horn LV, Liu K, Parker D, Emidy L, Liao YL, Pan WH, Giumetti D, Hewitt J, Stamler J: Serum lipid response to oat product intake with a fat-modified diet. J Am Diet Assoc. 1986, 86:759-764.

19. Karmally W, Montez MG, Palmas W, Martinez W, Branstetter A, Ramakrishnan R, Holleran SF, Haffner SM, Ginsberg HN: Cholesterol-lowering benefits of oatcontaining cereal in Hispanic Americans. J Am Diet Assoc 2005, 105:967-970. 
20. Maki KC, Beiseigel JM, Jonnalagadda SS, Gugger CK, Reeves MS, Farmer MV, Kaden VN, Rains TM: Whole-grain ready-to-eat oat cereal, as part of a dietary program for weight loss, reduces low-density lipoprotein cholesterol in adults with overweight and obesity more than a dietary program including low-fiber control foods. J Am Diet Assoc 2010, 110:205-214.

21. Zhao WH, Zhang J, Zhai Y, You Y, Man QQ, Wang CR, Li H, Li Y, Yang XG: Blood lipid profile and prevalence of dyslipidemia in Chinese adults. Biomed Environ Sci 2007, 20:329-335.

22. Li Z, Yang $R, X u G$, Xia T: Serum lipid concentrations and prevalence of dyslipidemia in a large professional population in Beijing. Clin Chem 2005, 51:144-150.

23. The Lipids Research clinics coronary Primary Prevention Trial result. I: Reduction in incidence of coronary heart disease. JAMA 1984, 251:351-364.

24. Grundy SM, Cleeman Jl, Merzc N, Brewer HB Jr, Clark LT, Hunninghake DB, Pasternak RC, Smith SC Jr, Stone NJ: National Heart, Lung, and Blood Institute; American college of cardiology Foundation; American Heart Association: Implications of recent clinical trials for the National cholesterol Education Program Adult Treatment Panel III guidelines. Circulation 2004, 110:227-239.

25. Odegaard AO, Kohw P, Grossm D, Yuan JM, Pereiram A: Combined lifestyle factors and cardiovascular disease mortality in Chinese men and women: the Singapore Chinese health study. Circulation 2011, 124:2847-2854.

26. Wang HJ, Zhang B, DUw W, Liu AD, Zhang JG, Wang ZH, Su C, Ma YX, Zhai FY: Trends of the dietary fiber intake among Chinese aged 18-45 in nine provinces (antonomous region) from 1989 to 2006. Zhonghua Yu Fang Yi Xue Za Zhi 2011, 45:318-322.

27. Krauss RM, Eckel RH, Howard B, Appel LJ, Daniels SR, Deckelbaum RJ, Erdman JW Jr, Kris-Etherton P, Goldberg IJ, Kotchen TA, Lichtenstein AH, Mitchw E, Mullis R, Robinson K, Wylie-Rosett J, St Jeor S, Suttie J, Tribble DL, Bazzarre TL: AHA Dietary guidelines: revision 2000: A statement for healthcare professionals from the Nutrition committee of the American Heart Association. Circulation 2000, 102:2284-2299.

28. Després JP: Intra-abdominal obesity: an untreated risk factor for Type 2 diabetes and cardiovascular disease. J Endocrinol Invest 2006, 29(3 Suppl):77-82.

29. Good CK, Holschuh N, Albertson AM, Eldridge AL: Wholegrain consumption and body mass index in adult women: an analysis of NHANES 1999-2000 and the USDA pyramid servings database. J Amcoll Nutr 2008, 27:80-87.

30. Newby PK, Maras J, Bakun P, Muller D, Ferrucci L, Tucker KL: Intake of wholegrains, refined grains, and cereal fiber measured with 7-d diet records and associations with risk factors for chronic disease. Am J Clin Nutr 2007, 86:1745-1753

31. Keenan JM, Pins JJ, Frazel C, Moran A, Turnquist L: Oat ingestion reduces systolic and diastolic blood pressure in patients with mild or borderline hypertension: a pilot trial. J Fam Pract 2002, 51:369.

32. Behall KM, Scholfield DJ, Hallfrisch J: Whole-grain diets reduce blood pressure in mildly hyper cholesterolemic men and women. J Am Diet Assoc 2006, 106:1445-1449.

33. Maki KC, Galant R, Samuel P, Tesser J, Witchger MS, Ribaya-Mercado JD, Blumberg JB, Geohas J: Effects of consuming foods containing oat betaglucan on blood pressure, carbohydrate metabolism and biomarkers of oxidative stress in men and women with elevated blood pressure. Eur $J$ Clin Nutr 2007, 61:786-795.

34. Davy BM, Melby CL, Beske SD, Ho RC, Davrath LR, Davy KP: Oat consumption does not affect resting casual and ambulatory 24-h arterial blood pressure in men with high-normal blood pressure to stage I hypertension. J Nutr 2002, 132:394-398.

\section{doi:10.1186/1475-2891-11-54}

Cite this article as: Zhang et al:: Randomized controlled trial of oatmeal consumption versus noodle consumption on blood lipids of urban Chinese adults with hypercholesterolemia. Nutrition Journal 2012 11:54.

\section{Submit your next manuscript to BioMed Central and take full advantage of:}

- Convenient online submission

- Thorough peer review

- No space constraints or color figure charges

- Immediate publication on acceptance

- Inclusion in PubMed, CAS, Scopus and Google Scholar

- Research which is freely available for redistribution

Submit your manuscript at www.biomedcentral.com/submit
C Biomed Central 